\section{Efficiency of Cryoprotectants for In Vitro and Ex Vitro Germination of Cryopreserved Jatropha curcas Seeds}

\author{
Alexandre Bosco de Oliveira ${ }^{1}$ \\ Department of Crop Science, Federal University of Ceará (UFC), Center of \\ Agricultural Sciences, Av. Mister Hull, 2977, Fortaleza, CE 60356-001, \\ Brazil
}

\author{
Wagner A. Vendrame \\ Tropical Research and Education Center, University of Florida, $18905 \mathrm{SW}$ \\ 280th St. Homestead, FL 33031
}

\section{Luciana Cardoso Nogueira Londe}

Agricultural Research Company of Minas Gerais (Epamig), Experimental Field in Gorutuba, Rodovia MGT 122, km 155, Nova Porteirinha, Minas Gerais, 39.525-000, Brazil

Additional index words. Cryopreservation, oil seeds, vitrification solution, seed physiological quality, seedling establishment

\begin{abstract}
To investigate the effects of different cryoprotectants on germination and seedling development of jatropha (Jatropha curcas $\mathbf{L}$.) seeds after cryopreservation, two experiments were performed under in vitro and ex vitro conditions. Nine treatments were used for both experiments, as follows: T1-No cryoprotectants (control); T2glycerol 2 м (20 minutes); T3-sucrose 0.4 м (20 minutes); T4-glycerol 2 м (20 minutes) + PVS2 (10 minutes); T5-glycerol 2 м (20 minutes) + PVS2 + phloroglucinol 1\% (10 minutes); T6-sucrose 0.4 м (20 minutes) + PVS2 (10 minutes); T7-sucrose 0.4 м (20 minutes) + PVS2 + phloroglucinol 1\% (10 minutes); T8-glycerol 2 м (20 minutes) + sucrose 0.4 м (20 minutes) + PVS2 (10 minutes); and T9-glycerol 2 м (20 minutes) + sucrose $0.4 \mathrm{M}$ (20 minutes) + PVS2 (10 minutes) + phloroglucinol 1\% (10 minutes). After cryopreservation, seeds without cryoprotectants (T1) or with sucrose 0.4 м + PVS2 (T6) returned the best germination percentages after seven days of in vitro culture, $29.5 \%$ and $25 \%$, respectively. However, they were not significantly different. For the ex vitro experiment, seed germination percentage was higher in organic substrate. These results indicate that cryopreservation of jatropha seeds can be accomplished without cryoprotectants, and faster germination is obtained in organic substrate.
\end{abstract}

Jatropha (Jatropha curcas L.) has been considered a promising species for biofuel production. However, jatropha is still considered undomesticated and breeding and genetic improvement programs are needed. In this context, germplasm collection and evaluation are essential for breeding new cultivars with high yield, good quality, and wide adaptation (Cai et al., 2010).

Conservation of seed-propagated plants is relatively easy for seeds with orthodox type of storage behavior, such as jatropha. In this case, the viability can be maintained by drying the seeds and storing at low temperatures. The exsitu preservation of orthodox seeds in gene bank has been the most effective strategy for plant genetic resources conservation. Today,

Received for publication 25 May 2015. Accepted for publication 29 June 2016.

We thank the Coordination for the Improvement of Higher Education Personnel (Coordenação de Aperfeiçoamento de Pessoal de Nivel Superior-CAPES, Brazil) and the University of Florida for providing funding to support this project.

${ }^{1}$ Corresponding author. E-mail: aleufc@gmail.com. about six million accessions are conserved worldwide in more than 1000 gene banks as ex-situ germplasm collections (Radhamani and Sivaraj, 2013). It is therefore important that investors, planning commercial production of biodiesel with jatropha seeds as feedstock, do not have to store the seeds for long time, especially under open air conditions as the oil yield and free fatty acid content are affected by storage time and improper storage condition (Akowuah et al., 2012).

Prada et al. (2015) emphasized the use of biotechnological techniques, such as micropropagation and cryopreservation, as relevant tools to improve the possibilities for multiplication of genotypes of interest and long-term conservation of germplasm. Cryopreservation of seeds allows the long-term preservation of biological material at ultralow temperatures $\left(-196^{\circ} \mathrm{C}\right)$ in liquid nitrogen (LN) or in its vapor phase (between $-154^{\circ} \mathrm{C}$ and $-196{ }^{\circ} \mathrm{C}$ ) (Araújo et al., 2016). This procedure reduces the metabolism drastically and allows the plant material to reach a state whereby cellular division is halted, keeping its feasibility for a long period (Kaviani, 2011; Reed, 2008).
The main event that limits the survival of cryopreserved tissues using conventional freezing techniques is the possible ice formation within the extracellular matrix of multicellular tissues (Taylor et al., 2015). Therefore, new protocols have been developed involving the use of cryoprotectants to allow cooling of plant cell contents into a vitrification state without the formation of ice crystals (Engelmann, 2011; Nadarajan and Pritchard, 2014; Taylor et al., 2015). The plant vitrification method involves the use of an extremely concentrated solution (7-8 M) of cryoprotectants [plant vitrification solution (PVS)] to allow plant tissues to reach a vitrification state and prevent ice crystal formation (Niino and Arizaga, 2015). The most applied vitrification solution is the PVS2, which contains $30 \%(\mathrm{w} / \mathrm{v})$ glycerol, $15 \%(\mathrm{w} / \mathrm{v})$ ethylene glycol, $15 \%(\mathrm{w} / \mathrm{v})$ dimethyl sulfoxide, and $0.4 \mathrm{M}$ sucrose in basal Murashige and Skoog (MS) medium (Matsumoto and Niino, 2014).

Cryoprotectants are important for cell survival, but they can also cause some complex stresses, such as osmotic injury and dehydration stress (Uchendu et al., 2010). Sugars, such as sucrose, trehalose, and glucose, have been used as cryoprotectants and are regarded as vitrification agents without causing toxicity to plant cells (Benson and Bremner, 2004). A more recently used cryoprotectant is phloroglucinol (1,3,5-trihydroxybenzene) or phloroglucin (PG tautomer), a benzenetriol that has growth regulating properties (Perez et al., 2016; Teixeira da Silva et al., 2013) and improves recovery of cryopreserved protocorms (Vendrame and Faria, 2011).

In jatropha, in vitro seed cryopreservation protocols have been developed, but some problems related to this procedure have been reported, such as decrease in seed germination percentage (Salomão et al., 2016), low development of explants in vitro from cryopreserved seeds (Prada et al., 2015), and seedlings with reduced vigor and significant increase in abnormal plants (Silva et al., 2012). Therefore, the development of new cryopreservation protocols using alternative cryoprotectant combinations could improve the efficiency of this technique. The present study was performed to investigate the effects of different cryoprotectants on germination and seedling development of $J$. curcas in vitro and ex vitro.

\section{Material and Methods}

Location, plant material, and seed sterilization

A total of 12 hybrid plants were selected from a jatropha field plot at the University of Florida's Tropical Research and Educational Center (TREC) $\left(25^{\circ} 50^{\prime} \mathrm{N}\right.$ and $80^{\circ} 50^{\prime} \mathrm{W}, 3.8 \mathrm{~m}$ above sea level), in Homestead, FL. The 4-year-old hybrid plants were obtained from intraspecific crosses between jatropha accessions from Costa Rica and Mexico. The cryopreservation experiments for this study were performed in the Ornamental Horticulture's laboratory and greenhouse, both at TREC (Fig. 1). 
$J$. curcas seeds obtained after crosspollination were collected from twelve 4-year-old hybrids and stored in paper bags under laboratory conditions for three days. The mean values for length, width, 100 seed weight, and water content of these 4-d-old seeds before the cryopreservation process in $\mathrm{LN}$ were 1.70 $\mathrm{cm}, 1.87 \mathrm{~cm}, 71.38 \mathrm{~g}$, and $6.9 \%$, respectively, which is suitable for this species (Salomão et al., 2016). Seeds were washed in distilled water, followed by surface sterilization with $1 \%$ Alconox (Alconox, New York, NY) solution, and three successive distilled water rinses. Then, seeds were transferred to a laminar flow hood and were sterilized with $3 \%$ sodium hypochlorite for $5 \mathrm{~min}$, followed by three 3-min rinses in sterilized distilled water.

\section{Seed cryopreservation}

After sterilization, seeds were dried on autoclaved tissue paper for $5 \mathrm{~min}$ and placed in $\mathrm{LN}$ for $96 \mathrm{~h}$. For each treatment, six Falcon $15-\mathrm{mL}$ conical centrifuge tubes $(11.8 \mathrm{~cm}$ length $\times 1.7 \mathrm{~mm}$ o.d.) containing five seeds each were used. Different cryoprotectants were evaluated, either alone or in 1:1 combination (v:v). Nine treatments were evaluated for both in vitro and ex vitro experiments, as follows:

\footnotetext{
T1-No cryoprotectants (control);

T2-Glycerol 2 м (20 min);

T3-Sucrose 0.4 м (20 min);

T4 Glycerol $2 \mathrm{~m}$ (20 min) + PVS2 (10 min); T5-Glycerol 2 м (20 min) + PVS2 + Phloroglucinol 1\% (10 min);

T6-Sucrose $0.4 \mathrm{M}(20 \mathrm{~min})+\mathrm{PVS} 2(10 \mathrm{~min})$; T7-Sucrose 0.4 м (20 min) + PVS2 + Phloroglucinol 1\% (10 min);

T8-Glycerol 2 м (20 min) + Sucrose $0.4 \mathrm{M}(20 \mathrm{~min})+\mathrm{PVS} 2(10 \mathrm{~min})$;

T9-Glycerol 2 м (20 min) + Sucrose $0.4 \mathrm{M}(20 \mathrm{~min})+$ PVS2 (10 $\mathrm{min})+$ Phloroglucinol 1\% (10 min).
}

After $96 \mathrm{~h}$ in LN, Falcon tubes were removed and seeds rapidly thawed in a water bath at $40{ }^{\circ} \mathrm{C}$ for $2-3 \mathrm{~min}$, and the cryoprotectant solutions removed from the tubes. Seeds were then washed in distilled water, dried on paper tissue for $5 \mathrm{~min}$, and experiments 1 and 2 carried out.

Experiment I: In vitro germination and seedling growth from cryopreserved seeds. After cryopreservation, the seed testa was removed (Danso et al., 2011), and the remaining cotyledon and embryo were placed in magenta G-7 vessels (Magenta Corp., Chicago, IL) containing MS basal culture medium (Murashige and Skoog, 1962) solidified with $7 \mathrm{~g} \cdot \mathrm{L}^{-1}$ agar $\left(\right.$ Fisher $^{\circledR}$, Chicago, IL) for germination. The medium $\mathrm{pH}$ was adjusted to 5.7 before autoclaving at $121^{\circ} \mathrm{C}$ for $15 \mathrm{~min}$ at $1.2 \mathrm{~kg} \cdot \mathrm{cm}^{-2}$. In vitro seed cultures were maintained under controlled environmental conditions; $27 \pm 2{ }^{\circ} \mathrm{C} ; 52 \mu \mathrm{mol} \cdot \mathrm{m}^{-2} \cdot \mathrm{s}^{-1} ; 16 / 8$ light/dark using Philips ${ }^{\circledR}$ LED top lighting (Fig. 1A).

Germination $(\mathrm{G})$, oxidation $(\mathrm{O})$, and contamination (C) percentages, as well as shoot length (SL) and root length (RL), and the number of roots (NR) of seedlings were evaluated at $7 \mathrm{~d}$ after sown (DAS). In addition, shoot fresh weight (SFW) and root fresh weight (RFW), as well as shoot dry weight (SDW) and root dry weight (RDW) per seedling were determined at the final evaluation of this experiment (14 DAS). SDW and RDW were determined after oven drying at $80{ }^{\circ} \mathrm{C}$ for $2 \mathrm{~d}$.

Experiment II: Ex vitro germination and seedling growth from cryopreservated seeds. This experiment was performed in the greenhouse assessing the same treatments used for the in vitro experiment. Seeds were sown in 1-L plastic black pots containing a commercial garden soil used as substrate (MiracleGro ${ }^{\circledR}$ Garden Soil All Purpose, NPK 0.09\%$0.05 \%-0.07 \%$ ). Germination was recorded every day from the date of sowing and continued till the germination ceased (Fig. 1B).

We used six replicates of five seeds each to calculate 1) the initial percentage of seeds that germinated $\left.\left[G_{\mathrm{i}} \%=(n i / N) \times 100\right] ; 2\right)$ the final germination percentage $\left[G_{\mathrm{f}} \%=(n f / N) \times\right.$ $100]$, where $n i$ and $n f$ were, respectively, the number of seeds germinated at first evaluation (4 DAS) or at the end of the whole experiment (10 DAS), and $N$ was the number of seeds included in the test; 3 ) the germination speed index [GSI $\left.=\sum(n i / t i)\right]$, where $t i$ was time (day $i$ ) and; 4) the average germination time $\left[\mathrm{AGT}=\sum(t i . n i) / \sum n\right]$, where $N$ is the final number of seeds that germinated and $n i$ was the cumulative number of seeds germinated by adjacent counts at times $t i$ (Sneideris et al., 2015). Germination was defined as the visible emergence of the seedling hypocotyl.

In the final assessment of this study (10 DAS), seedlings were uprooted carefully to estimate the SL, SFW, RFW, SDW, and RDW per seedling.

\section{Statistical design and data analysis}

Six replicates of five seeds each were used for each treatment in both experiments. Treatments were arranged in a completely randomized design. Data were normalized by the formula $\sqrt{ } x+0.5$ and subjected to analysis of variance. Means were separated by the
Tukey's test at 5\% probability using the statistical software Sisvar (Ferreira, 2014).

\section{Results}

Experiment I: In vitro germination and seedling growth from cryopreserved seeds. After cryopreservation, the best in vitro germination results were observed with jatropha seeds that were submitted to no cryoprotectants (T1) or to sucrose $0.4 \mathrm{M}$ and PVS2 (T6), with $29.2 \%$ and $25 \%$ germination after seven days of in vitro culture, respectively (Table 1). However, no significant differences were observed between those treatments during this first evaluation. In addition to germination, these results were the best for seedling development, showing higher values for $G_{\mathrm{i}}$, SL, RL, and NR (Table 1). By contrast, T3, T4, T5, and $\mathrm{T} 9$ showed lower germination percentages and poor seedling establishment in vitro (Table 1). Contamination had a significant effect on those treatments. Oxidation of seedlings was observed only in T7. However, that did not affect germination and seedling development (Table 1).

Despite the faster growth of seedlings observed 7 DAS from intact seeds (control) and from treatment $\mathrm{T} 8$, only the latter

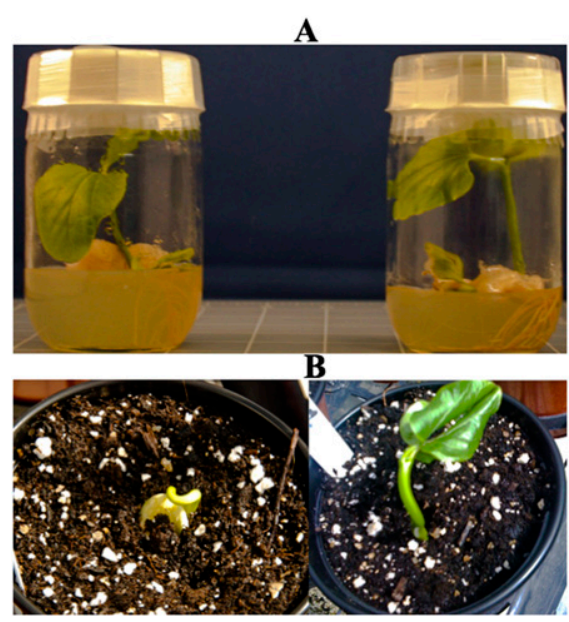

Fig. 1. In vitro (A) and ex vitro (B) germination of cryopreserved Jatropha curcas L. seeds.

Table 1. Germination $\left(G_{\mathrm{i}}\right)$, oxidation $(O)$, and contamination $(C)$ percentages, shoot length (SL) and root length (RL) and the number of roots (NR) of seedlings originated from jatropha seeds $7 \mathrm{~d}$ after sown in vitro in Murashige and Skoog basal media with agar.

\begin{tabular}{lcccccc}
\hline Treatment & $G_{\mathrm{i}}(\%)$ & $O(\%)$ & $C(\%)$ & SL $(\mathrm{cm})$ & RL $(\mathrm{cm})$ & NR $(\mathrm{cm})$ \\
\hline T1 & $29.2 \mathrm{a}$ & $0 \mathrm{~b}$ & $0 \mathrm{~b}$ & $1.21 \mathrm{ab}$ & $1.38 \mathrm{a}$ & $3.42 \mathrm{a}$ \\
T2 & $4.2 \mathrm{bc}$ & $0 \mathrm{~b}$ & $8.3 \mathrm{~b}$ & $0.33 \mathrm{ab}$ & $0.67 \mathrm{a}$ & $0.67 \mathrm{ab}$ \\
T3 & $8.3 \mathrm{abc}$ & $0 \mathrm{~b}$ & $33.3 \mathrm{ab}$ & $0.42 \mathrm{ab}$ & $0.08 \mathrm{a}$ & $0.67 \mathrm{ab}$ \\
T4 & $0 \mathrm{c}$ & $0 \mathrm{~b}$ & $41.7 \mathrm{ab}$ & $0 \mathrm{~b}$ & $0 \mathrm{a}$ & $0 \mathrm{~b}$ \\
T5 & $0 \mathrm{c}$ & $0 \mathrm{~b}$ & $79.2 \mathrm{a}$ & $0 \mathrm{~b}$ & $0 \mathrm{a}$ & $0 \mathrm{~b}$ \\
T6 & $25 \mathrm{ab}$ & $0 \mathrm{~b}$ & $0 \mathrm{~b}$ & $1.13 \mathrm{ab}$ & $1.18 \mathrm{a}$ & $3.33 \mathrm{a}$ \\
T7 & $16.7 \mathrm{abc}$ & $16.7 \mathrm{a}$ & $0 \mathrm{~b}$ & $0.83 \mathrm{ab}$ & $1.25 \mathrm{a}$ & $3 \mathrm{ab}$ \\
T8 & $20.8 \mathrm{abc}$ & $0 \mathrm{~b}$ & $0 \mathrm{~b}$ & $1.37 \mathrm{a}$ & $1.87 \mathrm{a}$ & $2.83 \mathrm{ab}$ \\
T9 & $4.2 \mathrm{bc}$ & $0 \mathrm{~b}$ & $83.3 \mathrm{a}$ & $0.33 \mathrm{ab}$ & $0.25 \mathrm{a}$ & $0.67 \mathrm{ab}$ \\
\hline
\end{tabular}

Means followed by the same letter in the same column are not significantly different according to Tukey's test $(P<0.05)$. T1 - no cryoprotectants (control); T2 - glycerol $2 \mathrm{M}(20 \mathrm{~min})$; T3 - sucrose $0.4 \mathrm{M}(20 \mathrm{~min})$; T4 - glycerol $2 \mathrm{M}(20 \mathrm{~min})+$ PVS2 (10 min); T5-glycerol $2 \mathrm{M}(20 \mathrm{~min})+$ PVS2 + phloroglucinol $1 \%$ $(10 \mathrm{~min}) ; \mathrm{T} 6$ - sucrose $0.4 \mathrm{~m}(20 \mathrm{~min})+$ PVS2 $(10 \mathrm{~min}) ; \mathrm{T} 7$ - sucrose $0.4 \mathrm{M}(20 \mathrm{~min})+$ PVS2 + phloroglucinol 1\% (10 min); T8-glycerol $2 \mathrm{M}(20 \mathrm{~min})+$ sucrose $0.4 \mathrm{M}(20 \mathrm{~min})+$ PVS2 $(10 \mathrm{~min})$; and T9-glycerol $2 \mathrm{~m}(20 \mathrm{~min})+$ sucrose $0.4 \mathrm{~m}(20 \mathrm{~min})+$ PVS2 $(10 \mathrm{~min})+$ phloroglucinol $1 \%(10 \mathrm{~min})$. 
Table 2. Germination $\left(G_{\mathrm{f}}\right)$ and contamination $(C)$ percentages, shoot length (SL) and root length (RL), the number of leaves (NL) and number of roots (NR), shoot fresh weight (SFW) and root fresh weight (RFW), shoot dry weight (SDW) and root dry weight (RDW) per seedling originated from jatropha seeds $14 \mathrm{~d}$ after sown in vitro in Murashige and Skoog basal media with agar.

\begin{tabular}{|c|c|c|c|c|c|c|c|c|c|c|}
\hline Treatment & $G_{\mathrm{f}}(\%)$ & $C(\%)$ & $\mathrm{SL}(\mathrm{cm})$ & $\overline{\mathrm{RL}}(\mathrm{cm})$ & NL & NR & SFW (mg) & RFW (mg) & SDW (mg) & RDW (mg) \\
\hline T1 & $37.5 \mathrm{a}$ & $25 \mathrm{ab}$ & $1.86 \mathrm{~b}$ & $1.83 \mathrm{ab}$ & $0.88 \mathrm{ab}$ & $2.5 \mathrm{ab}$ & $141.9 \mathrm{~b}$ & $20 \mathrm{~b}$ & $89.1 \mathrm{~b}$ & $1.98 \mathrm{~b}$ \\
\hline $\mathrm{T} 2$ & $4.2 \mathrm{~b}$ & $8.3 \mathrm{~b}$ & $0.55 \mathrm{~b}$ & $0.75 \mathrm{ab}$ & $0.17 \mathrm{~b}$ & $0.67 \mathrm{~b}$ & $55.5 \mathrm{~b}$ & $6.7 \mathrm{~b}$ & $38.4 \mathrm{~b}$ & $0.75 \mathrm{~b}$ \\
\hline $\mathrm{T} 3$ & $8.3 \mathrm{~b}$ & $45.8 \mathrm{ab}$ & $0.87 \mathrm{~b}$ & $0.58 \mathrm{ab}$ & $0.67 \mathrm{ab}$ & $0.83 \mathrm{~b}$ & $0 \mathrm{~b}$ & $0 \mathrm{~b}$ & $0 \mathrm{~b}$ & $0 \mathrm{~b}$ \\
\hline $\mathrm{T} 4$ & $0 \mathrm{~b}$ & $41.7 \mathrm{ab}$ & $0 \mathrm{~b}$ & $0 \mathrm{~b}$ & $0 \mathrm{~b}$ & $0 \mathrm{~b}$ & $0 \mathrm{~b}$ & $0 \mathrm{~b}$ & $0 \mathrm{~b}$ & $0 \mathrm{~b}$ \\
\hline T5 & $0 \mathrm{~b}$ & $79.2 \mathrm{a}$ & $0 \mathrm{~b}$ & $0 \mathrm{~b}$ & $0 \mathrm{~b}$ & $0 \mathrm{~b}$ & $0 \mathrm{~b}$ & $0 \mathrm{~b}$ & $0 \mathrm{~b}$ & $0 \mathrm{~b}$ \\
\hline T6 & $25 \mathrm{ab}$ & $0 \mathrm{~b}$ & $1.68 \mathrm{~b}$ & $1.93 \mathrm{ab}$ & $1.33 \mathrm{ab}$ & $4 \mathrm{ab}$ & $306.1 \mathrm{~b}$ & $43.3 \mathrm{~b}$ & $198 \mathrm{ab}$ & $6.42 \mathrm{ab}$ \\
\hline $\mathrm{T} 7$ & $16.7 \mathrm{ab}$ & $0 \mathrm{~b}$ & $0.86 \mathrm{~b}$ & $2.08 \mathrm{ab}$ & $1.17 \mathrm{ab}$ & $3.33 \mathrm{ab}$ & $226.8 \mathrm{~b}$ & $35 \mathrm{~b}$ & $157.6 \mathrm{ab}$ & $4.58 \mathrm{ab}$ \\
\hline T8 & $25 \mathrm{ab}$ & $0 \mathrm{~b}$ & $5.45 \mathrm{a}$ & $3.47 \mathrm{a}$ & $1.58 \mathrm{a}$ & $5.58 \mathrm{a}$ & $1156 \mathrm{a}$ & $303.3 \mathrm{a}$ & $315.2 \mathrm{a}$ & $20.4 \mathrm{a}$ \\
\hline T9 & $4.2 \mathrm{~b}$ & $83.3 \mathrm{a}$ & $0.33 \mathrm{~b}$ & $0.25 \mathrm{~b}$ & $0 \mathrm{~b}$ & $0.67 \mathrm{~b}$ & $0 \mathrm{~b}$ & $0 \mathrm{~b}$ & $0 \mathrm{~b}$ & $0 \mathrm{~b}$ \\
\hline
\end{tabular}

Means followed by the same letter in the same column are not significantly different according to Tukey's test $(P<0.05)$. T1 - no cryoprotectants (control); T2 -

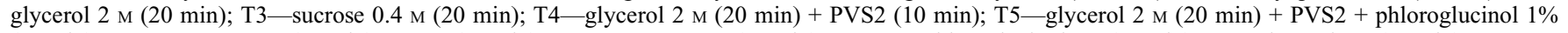

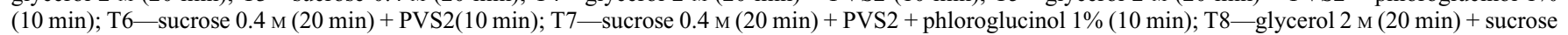
$0.4 \mathrm{~m}(20 \mathrm{~min})+\mathrm{PVS} 2(10 \mathrm{~min})$; and T9-glycerol $2 \mathrm{~m}(20 \mathrm{~min})+$ sucrose $0.4 \mathrm{~m}(20 \mathrm{~min})+\mathrm{PVS} 2(10 \mathrm{~min})+\mathrm{phloroglucinol} 1 \%(10 \mathrm{~min})$.

Table 3. Germination percentage at four $\left(G_{\mathrm{i}}\right)$ and $10 \mathrm{~d}$ after sown $\left(G_{\mathrm{f}}\right)$, germination speed index (GSI), mean germination time (MGT), shoot length (SL), shoot fresh weight (SFW) and root fresh weight (RFW), shoot dry weight (SDW) and root dry weight (RDW) per seedling originated from jatropha seeds $10 \mathrm{~d}$ after sown ex vitro in organic substrate at greenhouse.

\begin{tabular}{lccccccccc}
\hline Treatment & $G_{\mathrm{i}}(\%)$ & $G_{\mathrm{f}}(\%)$ & GSI & MGT $(\mathrm{d})$ & SL $(\mathrm{cm})$ & SFW $(\mathrm{g})$ & RFW $(\mathrm{g})$ & SDW $(\mathrm{g})$ & RDW $(\mathrm{g})$ \\
\hline T1 & $10 \mathrm{a}$ & $66.7 \mathrm{a}$ & $0.65 \mathrm{a}$ & $5.09 \mathrm{~b}$ & $6.86 \mathrm{a}$ & $2.23 \mathrm{a}$ & $0.95 \mathrm{a}$ & $0.21 \mathrm{a}$ & $0.023 \mathrm{a}$ \\
T2 & $0 \mathrm{~b}$ & $3.3 \mathrm{~b}$ & $0.02 \mathrm{~b}$ & $7 \mathrm{a}$ & $1.33 \mathrm{a}$ & $1.29 \mathrm{a}$ & $0.9 \mathrm{a}$ & $0.01 \mathrm{a}$ & $0.008 \mathrm{a}$ \\
T3 & $0 \mathrm{~b}$ & $0 \mathrm{~b}$ & $0 \mathrm{~b}$ & $0 \mathrm{c}$ & $0 \mathrm{~b}$ & $0 \mathrm{~b}$ & $0 \mathrm{~b}$ & $0 \mathrm{~b}$ & $0 \mathrm{~b}$ \\
T4 & $0 \mathrm{~b}$ & $16.7 \mathrm{ab}$ & $0.13 \mathrm{ab}$ & $6.17 \mathrm{ab}$ & $2.63 \mathrm{a}$ & $3.48 \mathrm{a}$ & $1.99 \mathrm{a}$ & $0.24 \mathrm{a}$ & $0.023 \mathrm{a}$ \\
T5 & $0 \mathrm{~b}$ & $26.7 \mathrm{ab}$ & $0.24 \mathrm{ab}$ & $5.83 \mathrm{ab}$ & $5.5 \mathrm{a}$ & $2.02 \mathrm{a}$ & $1.05 \mathrm{a}$ & $0.22 \mathrm{a}$ & $0.027 \mathrm{a}$ \\
T6 & $6.7 \mathrm{ab}$ & $43.3 \mathrm{ab}$ & $0.43 \mathrm{ab}$ & $4.98 \mathrm{~b}$ & $6.58 \mathrm{a}$ & $3.8 \mathrm{a}$ & $1.93 \mathrm{a}$ & $0.26 \mathrm{a}$ & $0.028 \mathrm{a}$ \\
T7 & $0 \mathrm{~b}$ & $16.7 \mathrm{ab}$ & $0.16 \mathrm{ab}$ & $5.14 \mathrm{~b}$ & $5.15 \mathrm{a}$ & $2.18 \mathrm{a}$ & $1.26 \mathrm{a}$ & $0.14 \mathrm{a}$ & $0.017 \mathrm{a}$ \\
T8 & $0 \mathrm{~b}$ & $23.3 \mathrm{ab}$ & $0.20 \mathrm{ab}$ & $6.95 \mathrm{a}$ & $4.98 \mathrm{a}$ & $3.93 \mathrm{a}$ & $1.83 \mathrm{a}$ & $0.2 \mathrm{a}$ & $0.02 \mathrm{a}$ \\
T9 & $10 \mathrm{a}$ & $40 \mathrm{ab}$ & $0.39 \mathrm{ab}$ & $5.19 \mathrm{~b}$ & $8.12 \mathrm{a}$ & $3.73 \mathrm{a}$ & $1.98 \mathrm{a}$ & $0.24 \mathrm{a}$ & $0.028 \mathrm{a}$ \\
\hline
\end{tabular}

Means followed by the same letter in the same column are not significantly different according to Tukey's test $(P<0.05)$. T1 — no cryoprotectants (control); T2 - glycerol $2 \mathrm{M}(20 \mathrm{~min})$; T3 - sucrose $0.4 \mathrm{M}(20 \mathrm{~min})$; T4-glycerol 2 м (20 min) + PVS2 (10 min); T5-glycerol 2 м (20 min) + PVS2 + phloroglucinol 1\% $(10 \mathrm{~min})$; T6-sucrose $0.4 \mathrm{~m}(20 \mathrm{~min})+$ PVS2 $(10 \mathrm{~min})$; T7-sucrose $0.4 \mathrm{~m}(20 \mathrm{~min})+\mathrm{PVS} 2+$ phloroglucinol 1\% (10 min); T8 - glycerol $2 \mathrm{~m}(20 \mathrm{~min})+$ sucrose $0.4 \mathrm{M}(20 \mathrm{~min})+$ PVS2 $(10 \mathrm{~min})$; and T9-glycerol 2 м (20 min) + sucrose 0.4 м (20 min $)+$ PVS2 (10 min $)+$ phloroglucinol 1\% (10 min).

provided the highest values for all variables that evaluated seedling development at 14 DAS, at the end of the experiment (Table 2). Treatments $\mathrm{T} 6$ and $\mathrm{T} 7$ showed similar results and characteristics to the control and $\mathrm{T} 8$ treatment, except for lower SL, SFW, and RFW values (Table 2). Similar to the results observed in the first evaluation, T3, T4, T5, and $\mathrm{T} 9$ showed the lowest values. That occurred because of relatively high perceptual of fungal contamination in this material. However, no seedling oxidation was observed in this final assessment in vitro (Table 2).

Experiment II: Ex vitro germination and seedling growth from cryopreserved seeds. The best ex vitro germination after cryopreservation of jatropha seeds was observed with the control treatment (T1) (Table 3). Germination percentages were higher at $4 \mathrm{~d}(10 \%)$ and $10 \mathrm{~d}(66.7 \%)$ after seeds were sown on substrate (Table 3). All other treatments showed no germination at $4 \mathrm{~d}$ after removal from cryopreservation. Treatments T6 (6.7\%) and T9 $(10 \%)$ showed similar results to the control for germination at $4 \mathrm{~d}$. For germination at $10 \mathrm{~d}$, most treatments were similar to the control, except for T2 and T3 (Table 3). Germination percentages were $10 \%$ at $4 \mathrm{~d}$ and $40 \%$ at $10 \mathrm{~d}$ after seeds were sown on substrate (Table 3 ).

The use of sucrose $0.4 \mathrm{M} \mathrm{(T3)} \mathrm{was} \mathrm{not}$ efficient for cryopreservation of jatropha seeds as no germination was observed (Table 3).

Despite the good results observed in T8 for in vitro conditions (Experiment I), this treatment presented slower germination when compared with control, T9, and T6 under greenhouse conditions in Experiment II (Table 3). No seeds germinated at 4 DAS $\left(\mathrm{G}_{\mathrm{i}}\right)$ for T8 and longer time $(6.95 \mathrm{~d})$ was needed to germinate (Table 3 ). The best treatments with cryoprotectants were T6 and T9, resulting in higher initial germination $(6.7 \%$ and $10 \%$, respectively) and final germination ( $43.3 \%$ and $40 \%$, respectively) percentages, as well as low mean germination time of $4.98 \mathrm{~d}$ for T6 and $5.19 \mathrm{~d}$ for T9 (Table 3). There were no significant differences among treatments for the variables that assessed seedling development, except for T3, which presented no germination, and subsequently no seedling development (Table 3).

\section{Discussion}

Experiment I: In vitro germination and seedling growth from cryopreserved seeds. Although cryopreservation of plant material in the form of seeds and zygotic embryos is currently widely used (Kaviani, 2011; Nadarajan and Pritchard, 2014; Silva et al., 2012), even the best treatments in this study resulted in low percentage of germination in vitro 7 DAS (T1 and T6) and 14 DAS (T1 and T8), varying between $25 \%$ and $37.5 \%$. This could be related to intrinsic traits of the seed, such as composition, moisture content, and tolerance to ultralow temperatures (Chmielarz, 2009; Das Bhowmik et al., 2011; Prada et al., 2015; Salomão et al., 2016).

Radhamani and Sivaraj (2013) emphasizes that the viability of orthodox seeds can be maintained by drying the seeds and storing at low temperatures, and jatropha shows orthodox seed storage behavior. Nonetheless, lipids present in the seed composition may make the seeds more sensitive to freezing in LN (Das Bhowmik et al., 2011; Salomão et al., 2016), as observed in this study. However, Chmielarz (2009) reports that oil seeds containing unsaturated fatty acids in its composition, such as jatropha, may have the negative effect of the transition phase during freezing attenuated. Nonetheless, cryopreservation has been indicated as an efficient conservation method for different lipid and not long-lived seeds (Michalak et al., 2013; Nadarajan and Pritchard, 2014; Prada et al., 2015).

For any cryopreservation protocol, success is determined by the recovery of viable propagules (Reed, 2008) and both oxidation and contamination can be relevant issues for the survival of seedlings in vitro. In this study, seedlings originated from seeds pretreated with sucrose $0.4 \mathrm{M}(20 \mathrm{~min})+$ PVS2 + phloroglucinol 1\% (10 $\mathrm{min})$ showed some oxidation symptoms in vitro (16.7\%) 7 DAS, but symptoms were reversed throughout the in vitro growth time, and no oxidized material was observed at 14 DAS. However, a significant percentage of contamination in vitro caused by fungus was observed 7 DAS for T3, T4, T5, and T9, and 14 DAS for T1, T3, T4, T5, and T9. Similarly, Salomão et al. (2016) reported significant reduction in percentages of jatropha seeds germination after exposure to $\mathrm{LN}$, such as $48 \%$ (whole seeds) and $57 \%$ (excised embryonic axes), being this attributed to fungal contamination.

This indicates that further studies are needed to improve sterilization procedures in protocols with cryoprotectants, which could reduce the contamination percentage in vitro, and subsequently death of plant material. 
At the end of $14 \mathrm{~d}$ of in vitro culture, treatment $\mathrm{T} 8$, comprised glycerol $2 \mathrm{M}(20 \mathrm{~min})+$ sucrose $0.4 \mathrm{M}(20 \mathrm{~min})+$ PVS2 (10 $\mathrm{min})$ was the most efficient for jatropha development in vitro, providing the best results for all variables. Similarly, Prada et al. (2015) reported that jatropha development was higher when embryos were pretreated with a mixture of cryoprotectants, including sucrose $0.3 \mathrm{M}$ and PVS2.

Benson and Bremner (2004) consider that sugars, such as sucrose, have been regarded as vitrification agents without causing toxicity to plant cells. Our results confirmed that the addition of sucrose with glycerol and PVS2 provided proper cryoprotection to the jatropha seeds. This indicates a potential synergistic effect of sucrose with glycerol and PVS2, which resulted in a successful vitrification process. It is also likely that the cryoprotectants acted by replacing water, changing the nonpenetrating freezing behavior of the charge solution by osmotically dehydrating the cellular interior. Subsequently, the reduced temperature restricted the mobility of the water molecules inside the cell, preventing the nucleation of ice crystals (Reed, 2008) and promoting better responses in vitro, as demonstrated in this study.

By contrast, despite the previous reports of phloroglucinol as an efficient cryoprotectant to enhance germination of orchids seeds and recovery of orchid protocorms (Galdiano et al., 2012; Vendrame and Faria, 2011), it did not promote such benefits for jatropha seed germination and seedling establishment in vitro in this study.

Experiment II: Ex vitro germination and seedling growth from cryopreservated seeds. In the present study, seed germination percentage was higher in organic substrate compared with in vitro germination. Similar results were reported by Prada et al. (2015), who highlighted that the development of jatropha seeds after cryopreservation was $100 \%$ in sand substrate with seedlings measuring $194 \mathrm{~mm}$ in length, compared with $86.6 \%$ and $28 \mathrm{~mm}$ in length for in vitro seedlings.

In this study, the use of sucrose as cryoprotectant apparently caused toxicity to plant cells, resulting in no germination and seedling development. However, sucrose has been effective to induce osmotic and colligative effects, i.e., reducing osmotic potential, leading to a reduction in the water content of cells to confer dehydration, freezing tolerance, or both (Benson and Bremner, 2004).

Either seeds nontreated (T1) or pretreated with glycerol $2 \mathrm{M}$, sucrose $0.4 \mathrm{M}$, PVS2, and phloroglucinol 1\% (T9) presented good results for germination in organic substrate in the greenhouse. It is likely that phloroglucinol played a relevant role in combination with the vitrification solution in T9, providing faster germination when compared with the treatment without phloroglucinol (T8), which in turn was the best cryoprotectant in vitro. Therefore, phloroglucinol's antioxidant properties (Benson and Bremner, 2004;
Kang et al., 2006) might have contributed to accelerate the germination ex vitro by reducing oxidative stress in cells of jatropha seeds.

The variations obtained in both experiments reflect the difficulty in determining the most adequate treatment for cryopreservation. Galdiano et al., (2012) emphasized that one of the main factors for successful vitrification is the adequate selection of cryoprotectants and the exposure time of the tissue to the vitrification solutions. This is essential to reduce the potential toxicity on plant cells and increase the recovery after storage in ultralow temperatures.

The relatively low germination and seedling development in vitro and ex vitro observed in both experiments may be correlated with potential harmful effects of cryopreservation on jatropha seeds. These results highlight the importance of further studies to improve cryoprotection of jatropha seeds during cryopreservation procedures.

Although cryopreservation provides stable, long-term, low-cost storage of plant material safe from diseases or environmental damage, storing plants at low temperatures does have some deleterious effects (Uchendu et al., 2010), as demonstrated in this study. Chilling and freezing injury promote many sublethal changes, such as metabolic uncoupling, which can then lead to increased production of free radical species (Day et al., 2000). These substances might cause severe damages to cell membranes, consequently affecting directly the seed germination and plant development (Oliveira et al., 2012). Some of these effects may have played a role in this study, as shown by no or low germination and poor seedling development.

In this study, the use of cryoprotective agents, such as sucrose, glycerol, and PVS2, together for cryopreservation of jatropha seeds may provide good responses for in vitro germination, especially regarding seedling development. Nevertheless, because of economic reasons and relatively good results observed for intact seeds (nontreated) in our experiments ex vitro, we recommend the cryopreservation of jatropha seeds without cryoprotectants for further faster germination in organic substrate under greenhouse conditions. This behavior may also be related to the classification of $J$. curcas, in terms of conservation because this species is considered orthodox (Radhamani and Sivaraj, 2013) and typically could maintain its viability by drying the seeds and storing at low temperatures.

\section{Literature Cited}

Akowuah, J.O., A. Addo, and F. Kemausuor. 2012 Influence of storage duration of Jatropha curcas seed on oil yield and free fatty acid content. ARPN J. Agr. Biol. Sci. 7:41-45.

Araújo, D.S., P.B. Luz, L.G. Neves, and S. Paiva Sobrinho. 2016. Seed cryopreservation of Passiflora species. J. Seed Sci. 38:248-253.

Benson, E.E. and D. Bremner. 2004. Oxidative stress in the frozen plant. In B.J. Fuller, N. Lane, and E.E. Benson (eds.). Life in the frozen state. CRC Press, Boca Raton, FL.
Cai, Y., D. Sun, G. Wu, and J. Peng. 2010. ISSRbased genetic diversity of Jatropha curcas germplasm in China. Biomass Bioenergy 34:1739-1750.

Chmielarz, P. 2009. Cryopreservation of dormant orthodox seeds of forest trees: Mazzard cherry (Prunus avium L.). Ann. For. Sci. 66:405-409.

Danso, K.E., N.T. Afful, C. Annor, and H.M. Amoatey. 2011. In vitro regeneration of Ricinus communis L. and Jatropha curcas L. for biofuel production. Biotechnol. 10:400-407.

Das Bhowmik, S.S., S. Kumaria, and P. Tandon. 2011. Long-term conservation through cryopreservation of immature seed of Mantisia spathulata and Mantisia wengeri; two endangered plants of north-east India. Cryo Lett. 32:498-505.

Day, J.G., R.A. Fleck, and E.E. Benson. 2000 Cryopreservation-recalcitrance in microalgae: Novel approaches to identify and avoid cryoinjury. J. Appl. Phycol. 12:369-377.

Engelmann, F. 2011. Use of biotechnologies for the conservation of plant biodiversity. In Vitro Cell. Dev. Biol. Plant 47:17-25.

Ferreira, D.F. 2014. Sisvar: A guide for its bootstrap procedures in multiple comparisons. Cienc. Agrotec. 38:109-112.

Galdiano, R.F., Jr., E.G.M. Lemos, R.T. Faria, and W.A. Vendrame. 2012. Cryopreservation of Dendrobium hybrid seeds and protocorms as affected by phloroglucinol and Supercool X1000. Sci. Hort. 148:154-160.

Kang, K.A., K.H. Lee, S. Chae, R. Zhang, M.S. Jung, Y.M. Ham, J.S. Baik, and J.W. Hyun. 2006. Cytoprotective effect of phloroglucinol on oxidative stress induced cell damage via catalase activation. J. Cell. Biochem. 97:609-620.

Kaviani, B. 2011. Conservation of plant genetic resources by cryopreservation. Austral. J. Crop Sci. 5:778-800.

Matsumoto, T. and T. Niino. 2014. The development of plant vitrification solution 2 and recent PVS2-based vitrification protocols. In: B.M. Reed (ed.). Proc. Second Intl. Symp. Plant Cryopreservation. Acta Hort. 1039:21-28.

Michalak, M., B.P. Plitta, and P. Chmielarz. 2013. Desiccation sensitivity and successful cryopreservation of oil seeds of European hazelnut (Corylus avellana). Ann. Appl. Biol. 163:351-358.

Murashige, T. and F. Skoog. 1962. A revised medium for rapid growth and bio-assays with tobacco tissue cultures. Physiol. Plant. 15:473-497.

Nadarajan, J. and H.W. Pritchard. 2014. Biophysical characteristics of successful oilseed embryo cryoprotection and cryopreservation using vacuum infiltration vitrification: An innovation in plant cell preservation. PLoS One 9:961-969.

Niino, T. and M.V. Arizaga. 2015. Cryopreservation for preservation of potato genetic resources. Breed. Sci. 65:41-52.

Oliveira, A.B., E. Gomes-Filho, J. Eneas-Filho, J.T. Prisco, and N.L.M. Alencar. 2012. Seed priming effects on growth, lipid peroxidation, and activity of ROS scavenging enzymes in $\mathrm{NaCl}$-stressed sorghum seedlings from aged seeds. J. Plant Interact. 7:151-159.

Perez, L.P., Y.P. Montesinos, J.G. Olmedo, R.B. Rodriguez, R.R. Sanchez, O.N. Montenegro, R.C.R. Escriba, D. Daniels, and R. GomezKosky. 2016. Effect of phloroglucinol on rooting and in vitro acclimatization of papaya (Carica papaya L. var. Maradol Roja). In Vitro Cell. Dev. Biol. Plant 52:196-203.

Prada, J., M. Aguilar, A. Abdelnour-Esquivel, and F. Engelmann. 2015. Cryopreservation of seeds and embryos of Jatropha curcas L. Amer. J. Plant Sci. 6:172-180. 
Radhamani, J. and N. Sivaraj. 2013. Conservation strategies and management of Jatropha germplasm. In: B. Bahadur, M. Sujatha, and N. Carels (eds.). Jatropha, challenges for a new energy crop. Vol. 2. Springer, New York, NY.

Reed, B.M. 2008. Plant cryopreservation: A practical guide. Springer, New York, NY.

Salomão, A.N., I.R.I. Santos, S.C.B.R. José, J.P. Da Silva, and B.G. Laviola. 2016. Methods to assess the viability of cryopreserved Jatropha curcas L. seed germplasm. Rev. Bras. Plantas Med. 18:391-398.
Silva, R.D.C., J. Camillo, and J.E. ScherwinskiPereira. 2012. A method for seedling recovery in Jatropha curcas after cryogenic exposure of the seeds. Rev. Biol. Trop. 60:473-482.

Sneideris, L.C., M.A. Gavassi, M.L. Campos, V. D'Amico-Damiao, and R.F. Carvalho. 2015 Effects of hormonal priming on seed germination of pigeon pea under cadmium stress. An. Acad. Bras. Cienc. 87:1847-1852.

Taylor, M., K.G. Brockbank, and Y. Rabin. 2015. Avoiding the problems of ice in tissues via vitrification. Cryobiology 71:170-171.
Teixeira da Silva, J.A., J. Dobránszki, and S. Ross. 2013. Phloroglucinol in plant tissue culture. In Vitro Cell. Dev. Biol. Plant 49:1-16.

Uchendu, E.E., S.W. Leonard, M.G. Traber, and B.M. Reed. 2010. Vitamins C and E improve regrowth and reduce lipid peroxidation of blackberry shoot tips following cryopreservation. Plant Cell Rep. 29:25-35.

Vendrame, W.A. and R.T. Faria. 2011. Phloroglucinol enhances recovery and survival of cryopreserved Dendrobium nobile protocorms. Sci. Hort. 128:131-135. 